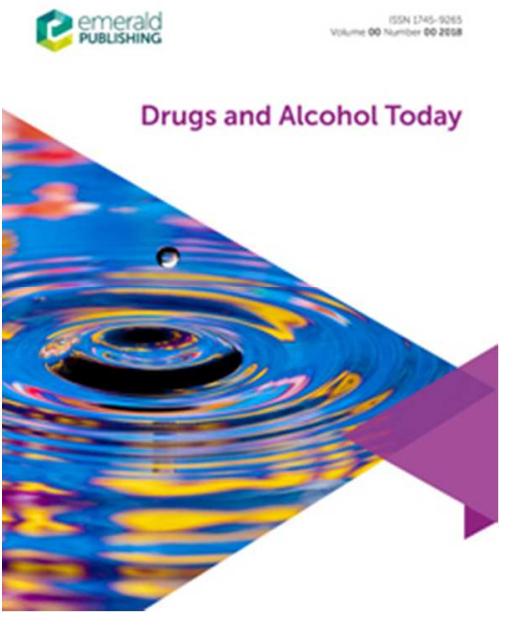

\title{
Being the change: Charting Greg de Hoedt's cannabis journey
}

\begin{tabular}{|r|l|}
\hline Journal: & Drugs and Alcohol Today \\
\hline Manuscript ID & DAT-01-2018-0001.R1 \\
\hline Manuscript Type: & Research Paper \\
\hline Keywords: & $\begin{array}{l}\text { cannabis, drug policy, medicinal cannabis, activism, cannabis social clubs, } \\
\text { Crohn's disease }\end{array}$ \\
\hline
\end{tabular}


2

3

4

5

6

7

8

\begin{abstract}
Purpose: To document a leading UK cannabis activist's efforts to bring about policy change and to convey his human story as a medical consumer. The paper contends that it is not enough to present evidence based policies (EBP) to effect change in drug policy, it is also vital to tell human stories, to develop narratives which speak to people's values.
\end{abstract}

Methodology: An in depth, unstructured interview was conducted between Dr Melissa Bone and cannabis activist, Greg de Hoedt in December 2017. The interview was recorded, transcribed and formed the basis of the paper, which was co-edited and co-created by both authors.

Findings: The paper charts Greg's journey from being a cannabis consumer - to being diagnosed with Crohn's - to being a cannabis activist. The paper interweaves a drug policy discussion with a personal narrative. It connects unique insights into Greg's life with the broader forces and institutions which influence cannabis policy at a local, national and international level.

Originality: Incorporating Greg's personal narrative within an academic platform integrates his experiential knowledge into the 'expert' evidence base. Alongside the potential of personal narratives to facilitate the production of knowledge, Greg's emotive story could help to shape the public's perception of cannabis, which could subsequently influence policy. 


\section{Being the change: Charting Greg de Hoedt's cannabis journey}

"[W]hoever you are if you are a human being with a voice, you can start to persuade people, and if your arguments are good enough and you never stop, you will make converts, and they will join you, and you will win...if you are brave, if you refuse to be defeated, there will be a ripple effect from your actions that you may never see - but it will be there, transforming lives."

(Hari, 2015: 296).

\section{Introduction}

It is not enough to present evidence to effect change in drug policy; it is necessary to tell human stories which people can relate to, to develop narratives which speak to people's values (Rolles, 2017). Prohibition persists because it engages in a moral war against some people who use some drugs. Cannabis consumers and other drug takers are portrayed as 'bad' and worthy of punishment, or else as 'addicts' needing help. This reality fails to account for the fact that the majority of drug taking is non-problematic and can serve a variety of functions which can be incorporated into an otherwise conforming lifestyle (Askew, 2016). Reform advocates find themselves at a disadvantage by relying solely on evidence-based policies. While these are essential to advance the regulatory process, what a society believes to be morally right almost always overrides any evidence presented to them (Haidt, 2012; Rolles, 2017). Arguing from a position of moral authority by engaging with drug taker narratives can help to shift public opinion. Certainly, the human stories of Alicia Castilla and Michael Fischer, medicinal cannabis consumers suffering immense pain, were instrumental to help legalise and regulate (medicinal) cannabis (Starling 2016; Bone, 2017). Telling these human stories helped to garner public sympathy, highlight legal injustices and lower the political costs for politicians to publicly promote reform.

Human stories are not only vital for shifting public opinion, they are also important to help integrate the perspectives of cannabis consumers and other drug takers in the reform process. Cannabis consumers and cannabis activists in particular have considerable experiential knowledge, something which the Uruguayan government recognised as important to give political legitimacy to their cannabis reform process (Bone, 2017). The voice of the drug consumer is often downplayed, despite the fact that many key issues for drug policy have a normative, moral aspect (Roberts, 2014). Engaging with the lived experiences, the values and opinions of drug takers facilitates a space to better connect policy to those directly affected. Drug policy researchers are beginning to develop participatory methodologies to input cannabis consumers' and other drug takers' experiential knowledge into the 'expert' evidence base to help legitimise policy outcomes (Lancaster et al, 2017; Ritter et al, 2018). Unfortunately, the UK government's Drugs Strategy (HM Government, 2010; 2017) presently infantilises drug consumers. The UK government's continued focus on "reducing demand, restricting supply and building recovery" presumes that all drug taking is problematic and that drug takers need to 'recover' from their addictions. There is no mention of the increasing phenomenon of cannabis regulation across the globe, nor the fact that the UK is the largest producer and exporter of medical cannabis in a UN board's most recent statistical report! (INCB, 2017). ${ }^{1}$ Instead, the government's latest strategy hones in on the need for a 'national recovery champion'. Similarly, their 2010 strategy dedicated space towards building 'recovery champions'. Arguably, it is no longer enough for the UK government to solely rely on the discourse of 'recovery' or 'recovery

\footnotetext{
${ }^{1}$ In 2000 the global production of cannabis for medical and scientific purposes was 1.4 tons. In 2016 this number increased to 209.9 tons, the UK is the main producer, with 95 tons ( $44.9 \%$ of the global total). Additionally, the UK continued to be the main exporter of cannabis, with 2.1 tons exported in 2016 (67.7 per cent of global the total) (INCB, 2017).
} 
champions' given the connotations of problematic use associated with this concept. Academics, policy makers, and other interested parties ought to encourage a shift towards recognising, identifying and telling the stories of 'reform champions' as well.

The following story was relayed to Melissa Bone by Greg de Hoedt at his home in Brighton in December 2017. Greg is a founding activist for cannabis social clubs in the UK and a 'reform champion'for the cannabis movement in the UK.

\section{Being a cannabis consumer}

My first use of cannabis began before I was diagnosed with Crohn's Disease but I had been suffering with the symptoms for quite a while. When I was fourteen I started getting really bad stomach pains, digestive issues, going to the toilet frequently, having a lot of cramps and I was swinging from having diarrhoea to having constipation. I was going to the doctors frequently and discussing my symptoms, but they didn't take it seriously. They put it down to me not liking school or that I had a bit of hypochondria. At fifteen my Mother read about Crohn's and suggested to the doctor that this might be what I have, only to be told I was "too young". If you look at the data of people who are diagnosed with Crohn's, though, I was in the perfect age bracket to be diagnosed with it. This went on for some time. At school when I was seventeen I was malnourished and really pale. My tutor actually thought that I was a hard drug user because I looked so run down, which was understandable as I had been a starting player on the basketball team, the goalkeeper for the football team, and a high jump finalist. I explained that I was just really ill and no one knew what was wrong with me. At this stage I was prescribed peppermint tablets to deal with the nausea and sickness. I felt like they were making everything worse so I stopped taking them.

Just prior to this first debilitating flare up, over the summer, I got a job in a call centre and I met some people there who smoked cannabis. They were all a bit punky and so was I at the time, playing in a band and sporting a seven-inch blue mohawk after my GCSEs. At that time I never liked weed, my parents brought me up to think that if you smoke weed you'll get onto heroin or crack, you know the gateway theory; the idea that you'll become an addict and you'll die and I really believed that. I was the one who told the drummer in the band "if you smoke weed you'll go mad" because I believed all the rhetoric and the propaganda. These guys in the call centre though, they were down to earth and cool. They had an answer for all my questions about weed and its uses and because they were all smoking around me on lunch break and they weren't the evil people that I had been warned about, I finally thought 'huh, I'll give it a try'. The joint was mixed with tobacco though, so I took a puff but didn't really get an effect other than choking on tobacco. I was against the use of smoking tobacco as well because my Granddad died from lung cancer.

That autumn my older cousin, James, came over from New Zealand to live with us for a while. He had always been an influence on me growing up introducing me to music, art and theatre productions that he took part in. James smoked it pure from a pipe and I noticed there was a big difference! I had much better effects from smoking it pure and I just really enjoyed myself. I instantly thought how could people think this is as bad as what they say? I made friends with other people who smoked and looking back it was a really socially positive experience for me. Everyone else was drinking beer and I didn't really drink because I never liked the taste. I enjoyed smoking though and I just became much happier and healthier. At the time I didn't equate that my cannabis use was having such a positive effect on my health. My health had been so up and down, I just thought I was in a good phase.

I carried on toking during my first year of university and I still wasn't diagnosed at this point. I was doing a degree in film studies (a degree that became very useful later down the line!) and I found a local hook up. I sat and smoked and I would write music, write scripts, draw, edit videos, I read books and I did my university work. I came back home to work at the weekends and I left the cannabis at university. I didn't want my family or my girlfriend at the time to know about it because she held the 
views I previously did. Then in my second year my girlfriend and I moved in together and I stopped consuming cannabis. I became really, terribly ill. My health took a serious nosedive, it just plummeted and no one knew why.

\section{Being diagnosed with Crohn's}

I was sent to the hospital with a sealed letter from my GP during a flare up and even though I probably shouldn't have opened it I did. He wrote, 'I'm sending him in just in case, but I think he's a hypochondriac!" I was shocked. I'd been telling them in great detail what had been happening to me and they still believed I was making it up! For the medical establishment not to have had their eye on this is bad. Eventually I saw someone after I was booked in for a gastroenterologist appointment at a military hospital in Camberley. I had a colonoscopy and immediately the doctor saw that I had extreme inflammation and he told me that I had Crohn's Disease. I said that I told the doctors that I had Crohn's from the age of fifteen and they kept saying you don't, you're making this up. By this point I'd had years of all this incorrect, useless or damaging medicine and all this suffering which I wouldn't have had to have gone through if I had just been investigated and diagnosed properly. The point of being diagnosed was a massive relief for me. I could finally stop worrying, "What is wrong with me? Is this all in my head?" When you've been constantly told that you're a hypochondriac you do start thinking am I actually mad? Thinking those thoughts can have serious effects on your health and on your personal relationships.

In good faith, I began taking the medication they prescribed me, but things got even worse. I was throwing up, getting mood swings, losing my concentration. I was on sixteen different drugs including strong opiates like tramadol, immunosuppressives, chemotherapy drugs, antidepressants, steroids, the lot. I kept thinking I can't keep taking all of these drugs they're just making me worse. I found out that I was violently allergic to these synthetic aspirins that they had me on called Pentasa. Although they're widely used in this area and they work for a lot of people, my body responded very badly to them. I was bleeding more than ever and frothing at the mouth after taking them. It was crazy and it's horrible just thinking back on it to be honest. I still wasn't smoking cannabis during this time period and I stopped taking my antidepressants when I left them at my parents during a home visit. My head was absolutely frying, buzzing, I felt like I was having loads of little electric shocks going on up there. I think I must have been going through a form of serotonin syndrome, my brain receptors were looking for serotonin that just wasn't there because I wasn't taking my antidepressants. It was a horrible feeling and I was on quite a high dose.

I had a motorbike accident while I was withdrawing from my antidepressants. Weeks before the accident I had two sets of thoughts repeatedly going on in my head: should I start smoking weed again or is it best to stay away from it? I wasn't sure whether my use of cannabis had actually caused my Crohn's Disease and at the same time I was also wondering whether it could help cure it. After my motorbike accident I literally lifted my helmet up and thought "fuck this I'm going to start smoking weed again. I don't care about my life anymore and if I die I don't care, I just want to smoke some weed because it was something I could actually enjoy." I went back to my home town and asked a friend to help me find some, I didn't realise that it would sort my head-buzzes out. I still had no idea about the medical effects of cannabis at this point. Not long after I found cannabis again I started realising that I wasn't going to the toilet twenty times a day, that I was getting away with eating certain foods that I probably shouldn't be eating - I was generally starting to feel better again.

I realised that I needed to look into this a bit more. I googled cannabis and Crohn's and I found videos that showed how cannabis can help. I remember feeling really angry that this information had been kept from me, I became really evangelical and that put people off me big time. I started wondering: how can I get through to these people? At the same time I wanted to find out as much information as I could. This was how I first started getting into activism. 


\section{Reaching out}

I searched online and I came across some older cannabis activists in the UK. I wrote one of them a really heartfelt letter and I reached out saying what I thought we could achieve in the UK and what we could do. I hoped that we could look at what was being done in the US and try and bring that ethos over here. I didn't get much of a response. It made me think about why we're in such a bad situation in the UK. This all happened around the same time that Jackie Smith, the then Home Secretary in the UK, reclassified cannabis from a Class $\mathrm{C}$ to a Class B drug. I remember thinking "how utterly typical I've just started smoking weed again and they've just made it even more illegal - you have got to be kidding me!"

I started finding people on Facebook who were getting involved in discussions about cannabis and about using cannabis medicinally. I left comments on threads and I was getting likes. I felt like I had a voice that people listened to and I felt like I was making sense. I thought I need to find more people like me and since I couldn't in the UK, I reached out to the US by searching for podcasts on cannabis. I came across Radical Russ's NORML Daily Audio Stash (NORML, n.d.). It was an hour of cannabis talk every day, five days a week. Russ was also setting up the NORML (National Organization for the Reform of Marijuana Laws) Chapters in the States. I listened to Russ for a year and then he started a live chat which I jumped on. I wanted to try and speak to as many people as possible who were interested in cannabis and the cannabis movement. These guys on the live chat were agreeing with me that Russ made so much sense and that he was giving them the confidence to do something to change the cannabis laws in their States too. I told them that nothing was happening over here and they encouraged me to get on it! I realised that if I wanted to get anything done I was going to have to do it myself.

I began writing blogs, doing podcasts, I started a YouTube channel and my phone has not stopped buzzing since the day I put my first podcast up. I was getting constant notifications from all over the world. The people that I had been listening to, that I had been reading about and who had inspired me were sharing my stuff! My first podcast said that this was a war and that there are going to be fallen soldiers along the way. We can't just expect change and that if we want change we're going to have to make it happen ourselves. I listened to my first podcast a while back and I was surprised at how softly spoken and calm I was! People could hear the seriousness in my voice though and people were like "shit this guy is reaching out". No one else is fighting in the UK and this guy is sending out an SOS, this was my message in a bottle. People thankfully heard it and it totally changed my life. I was producing a new show every week. I'd get home from work and at the weekend I'd write it, get it live and wait for the phone to go nuts. I was getting mini awards from the podcast service that I was on because I was smashing the charts. I got a 'movers and shakers' award and I liked that, it gave me a good ethos. I was like yeah you are a mover and shaker, you're shaking things up and making things move!

I took that ethos going forward and I was connecting with people from all over the world. Activists around the world taught me how to target things more precisely in the UK. So I began doing stories from Manchester, from Liverpool, from Birmingham - I was trying to connect everyone. If I talked about the UK and put that in the title people were going to click on it. If they searched for the UK and cannabis, or their local area and cannabis, the SEO (search engine optimization) would bring it up. A few people got in touch with me in the UK. They weren't involved in any movement or cannabis scene before but they heard my podcasts and they were saying "I'm like you, I'm suffering the same thing. Let's work together." This was the birth of the UK's cannabis social club movement as it is now. Our demands to assert our right to health have brought UK cannabis activism out of a metaphorical dark age.

While everything seemed to be coming together with reaching out for people online, reaching out to people closer to home was a different story. I felt stigmatised by all of my family and my friends. I 
deleted my old Facebook account because people were telling me not to talk about this stuff; family and friends that I'd had for years were unfriending me and I thought what have I done to deserve this? I've always had your back, I'm going through something bad here and you don't even want to be my friend over it. I'm not asking for your advice, I'm just saying can you hear me out? Do you not understand what I'm going through here? They didn't understand and I don't have any people around from my former life now - schoolmates, university mates etc. Years ago people didn't want to talk about cannabis, but you can have a conversation about it in public now without worrying whether people are going to think something bad about you, or say something, or that the police are going to rumble you. The tension back then was much higher, people would hide their spliff walking down the street, and in some parts of the UK people are much more brazen about it now.

Although, I do feel like people who use cannabis medically are stigmatised. Even in the medical community it feels like you're the dirty one, you're the immigrant, etc. You feel that second class citizenship and when you say these things, especially in front of minority groups', people can get really offended and say, "You don't know what it's like to be a second class citizen". Maybe I don't, but to be put down so much within my own culture, within my own group of people, it's made me really empathise with other social movements like LGBTQI activists for example because I suffer a stigma too. My own doctor won't treat me because I use cannabis. That's a stigma that I suffer and I'm just another human being, you can't treat me differently just because I use cannabis.

Five years left to live

Around this time my health really declined again, largely because the quality of the cannabis that I could get hold of was getting worse. I had to stay in hospital and the doctors kept trying to tell me that my cannabis use was making my Crohn's worse. I brought some books with me into the hospital because I knew they were going to say that. I was 22 and in a hospital bed, in a room with all the old people. The doctor and nurse came in one day after I had completed a series of tests and been under observations. They said that they were really sorry to tell me this, but that I had stricturing so badly from my stomach all the way down, both the inside and the outside of my intestines were inflamed. They wanted to put a balloon inside my intestines to inflate them and to get some food moving down, but the stricturing was so bad that they couldn't even get that in there. Their 'remedy' was to take out everything from the bottom of my stomach down and sew me back up. They said: "We'll have to feed you from a feeding tube directly into your blood, because you won't have anywhere to digest your food and water, your artery will collapse after five years and unfortunately you will die."

I said "What?!" They repeated, "You've probably got five years left to live I'm really sorry to tell you this." I'm like, "Fuck off! No way! Are you shitting me? No I need cannabis, just prescribe me cannabis. I'll have Sativex please or Marinol." They told me I couldn't have that. I said, "So you're telling me there's medicine in this country that I know works and that I can't have it?" The hospital pharmacist came and spoke to me because I asked for specific cannabis drugs and he said, "Yeah you can't get either of those, you need to have MS or cancer to use those." I said, "But I know this works for me!" He replied, "I know, my brother's got Crohn's, he uses cannabis and it's the only thing that works for him but I can't do anything."

At this point I knew I wasn't mad if the hospital pharmacist was saying that too. So I started reaching out even more online and telling people my situation. Although I didn't realise it at the time people love drama! Everyone flocked to it and my friends in the US were encouraging to go to the US to medicate. I didn't think I was healthy enough to go out there but I rested for a few months in hospital and then at home. I went back to work just to save enough for a plane ticket and I carried on doing my podcasting.

\section{Being an activist}


At the beginning of 2011, after being given that life-changing news, I was invited to attend an SSDPUK (Students for Sensible Drugs Policy) conference by Levent Akbulut, as he listened to my podcasts. This was the first time I felt involved in drug policy reform more broadly. Levent said, "You're an activist, you" and I thought, "Am I?!" I saw Niamh Eastwood, the executive director from Release speak there as well, and I was really moved by what she and the other speakers had to say. That conference was the catalyst for me. I had just been told that I had five years left to live and I was in the mode that I needed to do everything that I could to change things because no one else was going to do it for me. I made a hard and fast decision that looking back on now, I really only had one option. Moved to tears by the truth about just how bad prohibition can be for some people, I called my boss and handed in my notice. I had just about enough money to buy a flight out to the US and one more pay check to come. I needed to get out to the US to study and experience all of the regulatory initiatives going on there to see how they could fit into a UK context.

\section{Going to the US}

When I went over to the US the activists that I'd been following saw me and they knew who I was. They would say, "Hey Greg glad to see you made it out here". I thought, wow people do listen. That gave me the confidence to really make the most out of my experience the US. I went around using the skills I developed in university as a cameraman and as a video maker. I travelled around the US and I filmed people's cannabis gardens, I went to conferences, I met doctors, and I made videos of patients and drug war victims' stories in exchange for a place to stay and for some meds. The US cannabis community was very welcoming, it was a very reciprocal experience. Although there is a smaller community like that in the UK, over there it was just fully blown - "Hey brother, here's the food, here's the dabs, here's the bed!" I was going from place to place so it was really nice to be welcomed like that.

I went to Colorado first and experienced Denver. Then I went to California - San Francisco, Oakland, LA, Orange County and Mendocino. I did this because I wanted to find out everything. There were so many different initiatives going on. I wanted to find out as much as I could about every one of them so that I could see how this could work in the UK. I was always thinking how would this work in our world? Would people accept this in the UK? But you can't just go and look for what you want, you've got to experience everything to really find out about these initiatives. I intentionally set out with the view to get outside of my comfort zone as I didn't believe I would find the truth in what I already knew.

From California I went to Washington which was a nineteen hour trip on a greyhound bus. I was always very open about what I was doing and I spoke to different people along the way to understand what every day Americans thought of the emergence of cannabis legalisation. Washington was a totally different experience from California. In California you could get a medical card from a doctor really easily, you could get a medical card just for having writer's block! In Washington you could grow a small number for yourself or else you would have to have a caregiver, the number of plants that they could grow was limited and they had to be grown in a locked room with your medical exemption placed on the wall clearly. There were three dispensaries in the whole area that I was in but they weren't the same as in Denver or in San Francisco, rather there was a man in an office and some jars of herb. In reality, to pick up, you had to get it from someone you knew who grew at the time, which was technically illegal then. I found it hard to buy any decent weed and I was getting really rundown in my health for the two weeks that I was smoking it. I got to experience what patients were suffering in Washington just by being one and by being there. I noticed the collective action was much less vibrant in this part of the State compared to the movement in Seattle, which is home to Hempfest. There wasn't much going on to inspire locals to make a difference.

When I returned to Denver, six months after first arriving, a plant tagging model that originated with a Sheriff in Mendocino, California had been advanced and implemented state-wide. I had heard about 
Doug Fine (2012), a New York Times journalist, who later went on to publish Too High to Fail about his experience. Doug followed medical cannabis farmers operating in Mendocino. The Sheriff, Tom Allman had implemented a regulatory model, where medical cannabis growers were required to put special tags around their plants which protected them from being raided. These farmers could have up to 99 plants growing in a Collective (one under the federal felony limit). They had monthly inspections from deputies and they would have to pay up $\$ 8,500$ to be part of the program. The county wasn't making enough money and the police force was threatened with being unfunded. Everyone knew that cannabis was sustaining the economy, so Sheriff Tom thought it made sense to tax the cannabis farmers. The Sheriff knew that if he busted these guys', people on the police force could lose their jobs! Ironically, these farmers were keeping the police force running, they were keeping schools and libraries running, people had food on the table because of this industry. Even though the Sheriff didn't like marijuana, he knew it would be legal eventually. He made a deal with the DEA flyover patrol to leave the farmers alone if they displayed the flag signifying the tagged model, which the DEA were fine with because they're going after the 'big boys', not the medical marijuana growers. I thought that we needed to do something similar in the UK since the situation wasn't all too dissimilar.

What had initially started in California had spread to Colorado. Denver had installed a seed to sale CCTV tracking system for commercial medical cannabis. Every plant had a different serial number, you knew how much it weighed, who trimmed it and the batch number in case there was any contamination at the different growing or harvesting stages. There was accountability all the way down the line to ensure high quality and to prevent it being leaked onto the illicit market (something I had witnessed in other states). Colorado also introduced a badged licensing system at the same time. In order to work in a legally licensed facility you had to have a badge. However, the problem was that you couldn't get a badge if you had already committed a federal offence. So a few of my close friends who had been busted for using cannabis medicinally in the past were now excluded from the legalisation and regulation process. It put them off legalisation because they felt betrayed: "Wow, we've built this industry and now we're being screwed out of it." Of course that's happening everywhere today, but the first time I saw it happening was over in the US seven years ago.

Incidentally, my friends in Mendocino have reported that they have effectively lost their right to grow, since California legalised and regulated recreational cannabis in 2018. The California Growers Association, a trade group representing cannabis farmers, filed a lawsuit in January 2018 against the state, for failing to support small-scale growers in practice. While the California Department of Food and Agriculture is not issuing licenses larger than one acre before 2023, as agreed in the Adult Use of Marijuana Act (Proposition 64), it is allowing growers to effectively obtain unlimited small licenses; which detrimentally impact the smaller cannabis farms (The California Growers Associationv. California Department of Food and Agriculture, Gov. Code, § 11350; Code Civ. Proc., § 1060; For a full report on the barriers smaller farms face also see: The California Growers Association, 2018).

\section{The UKCSC}

I wanted to draw from my experience in the US and apply it here. I posted a blog in 2011 entitled 'Grow your own cannabis community' which went viral on social media (de Hoedt, 2011). I wanted to implement cannabis social clubs (CSCs) in the UK, draw from the model in Spain and from what I'd seen in the US, and follow the guidelines for the CSC model that the European Coalition for Just and Effective Drug Policies (ENCOD) (2011) had just put out. Around thirty people got in contact from around the UK who wanted to get involved. My activist friends (who I had met through podcasting) and I put everyone in a group online. We travelled around the country arranging meet ups and trying to connect people. This was the start of the UKCSC (n.d.).

In the early stages we didn't run like the cannabis social clubs in line with the ENCOD's (2011) definition: 
'Cannabis Social Clubs consist of members, adult citizens who organise the cultivation of a limited amount of cannabis to satisfy their personal needs. Thus a closed circuit is established between producers and consumers, where certain requirements are met concerning health, safety, transparency and accountability.'

The clubs didn't grow cannabis at first, we were more concerned with connecting people and growing a movement from the grassroots. I was also in touch with Jason Reed, the executive director of LEAPUK (Law Enforcement Against Prohibition). He suggested that we set up NORML-UK, since I already had the contacts with the people who had set up Chapters in the States, like Radical Russ. We envisioned that NORML-UK (n.d.) would work on a national scale and help us connect with the broader political networks that reform would need. Whereas the UKCSC was more on the ground, operating at the local level, connecting people and advising them about the sentencing guidelines and the amounts you could potentially grow before you're looking at prison time. No one was putting out any helpful information for growers and consumers the way that activists did in Europe and the US. Joop Ooman, the late Executive Director of ENCOD advised me to "take any quantity amounts your government have announced and use them to push for decriminalisation". Nine plants is still technically considered a domestic operation in the UK, which in theory means you shouldn't end up in prison (Sentencing Council, 2012). I thought that if there were sentencing limits then the cannabis movement could use these to push for quasi-decriminalisation for a certain amount of cannabis. That's effectively happened in other countries - although unlike here they've had certain amounts of cannabis fully decriminalised.

At the same time, the popularity of NORML-UK exploded. We set up a successful Global Cannabis March in Cardiff, and we had endorsements from both Howard Marks and Release and it brought many clubs together for the first time. Unfortunately, NORML-UK fell down because of interorganisational politics and personal disagreements. Some of the activists broke off and formed other organisations away from the UKCSC. Although NORML-UK has taken more of a back seat approach in recent years, it still plays a role in the national reform effort. It can be quite divisive in the cannabis movement. I would love it if we all could fight for the same message.

I threw all of my energy behind the UKCSC. A few years later, after the number and the size of the clubs had grown, Stuart Harper and I took the collective evidence the UKCSC had and wrote a model inspired by the Mendocino tagged plant model and linked it to the nine plant sentencing guideline limit (for more information see Cedar, 2016; 2017; de Hoedt 2016). Transform Drug Policy Foundation's practical guide on how to regulate cannabis really influenced our approach too (Rolles and Murkin, 2013). There are now over 150 CSCs registered with the UKCSC. I thought we just need to show in a self-regulatory way that home growing is safe and possible. If people use our model and their plants are tagged, then they become a member of the first cannabis growers union in the UK, and having many growing under the same model, as opposed to many growing under no model shows some respect for regulation. Our advice means the sentencing bracket you are in is considered soft as it is non-custodial. It's a harm reduction initiative at the end of the day. If you're going to get busted get busted for something. Help us make some change. I want us to grow within this model to show that we are responsible citizens, and that we are not criminals, even though the law has labelled us this way. We created a really detailed Operations Manual which covers everything including: the UKCSC's constitution, detailed models for growing and selling cannabis at fair trade prices, harm reduction measures and standardised posters designed to inform the police of the model (UKCSC, 2014).

As the chairperson, I've tried to use the UKCSC as an activist, crowdsourcing movement, where local club memberships would help pay for services and things we need like legal representation as a national group. Memberships could also pay for campaign messages and public events. My idea was that if you start with a localised movement then all these groups would build up, creating a bigger movement. Even if some groups fall down, they wouldn't be able to stop us, they could try and kill us 
off but the model would live on. That is the ethos behind the organisation. My grandad is from India and I've looked into Indian culture. Ghandi's philosophies had inspired me as a young person - 'be the change', create the world that you want to see.

That's the sword that I live and die by because this is killing me, it wears me down. I'm not the same person that I was, when I had that energy, when I first started this. I'm fighting so many entities within prohibition, which prohibition has actually created. People have a vested interest in maintaining prohibition or else they've got no interest in trying to help it end. For example, prohibition makes money for both the criminal justice system and the growers. It's not because growers want to keep people addicts or anything like that. They just want to keep the money that they're making. Those who look to the US know that if things change the profits of prohibition are going to stop flowing. Likewise, some of the CSCs aren't getting behind the ethos of the model, it's about the people and the product, not 'product over people'. The 'social' in cannabis social clubs doesn't mean 'not medical'. It also doesn't mean 'get smashed', it's about interacting and helping people and being human. Instead, these clubs are more like 'shadow clubs' (Decorte, 2015: 128), they're running themselves like a business, selling strains for extortionate amounts and they don't see anything wrong with that. They're not growing in line with the model and there's no safety or accountability. I'm now looking at how to develop a verification system, so that the CSCs following the UKCSC model can be more easily identified, and consumers will know that they are trustworthy and are not operating to take advantage of the sick and vulnerable. People may not be aware where this started in the UK but they have seen the waves and they want to find out more.

\section{Medican}

In any event, I want to keep my activism moving forward. My friend and colleague Lloyd Eggs is working closely with Suver Nuver, a foundation with nine medical social clubs in the Netherlands (de Hoedt, 2017). They've generated a lot of money through the memberships of over 7,000 people. They have to spend it on their stated aims; legalisation, information and education. They wanted to know how they could help us because they have so many people in the UK contacting them and asking for their help. When you think about it, the Netherlands is only a 45 minute flight away and people are willing to risk bringing some cannabis back with them, or posting it back, because they put their health first.

Those contacting Suver Nuver aren't 'stoners'. They're middle class, middle aged, or older people with cancer or with other serious illnesses and no one else can help. They don't want to go to a coffee shop or look at Buddha statues or a Shiva dancing in the window. That puts people off. Both the UK and the Netherlands are conservative countries, and the demographic contacting Suver Nuver aren't interested in those things, but they do need information and some support. In order to put a face on cannabis that people find welcoming, Suver Nuver have given us the funds to create Medican Campus (n.d.): "A home for medical cannabis education in the UK. A platform for patients, activists and reformers to share knowledge, and facilitate change."

The Medican facility will be in Brighton. It will be home to a cannabis library and art gallery, a large group work space, and it will also host cannabis education seminars for the public and healthcare professionals from a number of sectors. The space will allow me to bring all the elements of the last eight years of activism together and reboot my multimedia outreach. I've built up a network over the years which will allow us to invite doctors from America and Europe, specialists from GW Pharmaceuticals, drug policy reformers etc. to come and speak, to educate and share information with people in a digestible way. We're going to take peer-reviewed cannabis information and make it accessible for patients and caregivers because the internet can be a minefield. The plan is to open Medican Campuses in six different countries so far, and we should hopefully be up and running in Brighton by the time you read this, so watch this space! 
1

2

3

4

5

6

7

8

9

It's been eight years since I came off sixteen different types of pharmaceutical drugs and three years on from when I should have been pronounced dead. People are starting to wake up to the idea that cannabis is a medicine. Legalisation is inevitable if we keep on fighting for it.

\section{References}

Askew, R. (2016) "Functional fun: Legitimising adult recreational drug use" International Journal of Drug Policy, 36(1): 112-119.

Bone, M. (2017) "Human rights, Politics and Power: The case of the UK's Cannabis Social Club Movement" Paper presented at the 11th International Society of Drug Policy (ISSDP) conference, May 2017, Aarhus, Denmark; Paper presented at Breaking Convention conference, June 2017, Greenwich, London, also see: https://www.youtube.com/watch?v=YHrXH01AHsU (accessed 25 January 2018).

The California Growers Association, (2018) "An emerging crisis: Barriers to entry in California cannabis"https://d3n8a8pro7vhmx.cloudfront.net/emeraldgrowers/pages/3249/attachments/original/15 19106158/An Emerging Crisis.pdf?1519106158 (accessed 16 March 2018).

The California Growers Association v. California Department of Food and Agriculture, Gov. Code, $\S$ 11350; Code Civ. Proc., § 1060 (suit filed 22 January 2018)

https://d3n8a8pro7vhmx.cloudfront.net/emeraldgrowers/pages/523/attachments/original/1516753445/ 18.01.22_Complaint_FINAL.pdf?1516753445 (accessed 16 March 2018).

Cedar, A. (2016) "UK's Cannabis Social Clubs Come of Age", available at: http://volteface.m2e/features/ukcsc-general-meeting/ (accessed 23 January 2018).

Cedar, A. (2017) “How British Weed Growers Are Avoiding Prosecution”, available at: https://www.vice.com/sv/article/qkmwdm/how-british-weed-growers-are-avoiding-prosecution (accessed 23 January 2018).

Decorte, T. (2015) "Cannabis social clubs in Belgium: Organizational strengths and weaknesses, and threats to the model" International Journal of Drug Policy 26(1): 122-130

de Hoedt, G. (2011) “Grow your own Cannabis Community”, available at: https://cannabiscureuk.wordpress.com/2011/12/24/grow-your-own-cannabis-community/ (accessed 23 January 2018).

de Hoedt, G. (2016) "Medical Cannabis: Collectives for Compassionate Reasons", available at: https://ukcsc.co.uk/medical-cannabis-collectives-for-compassionate-reasons/ (accessed 24 January 2018).

de Hoedt, G. (2017) “A Suver Nuver Experience: The Cannabis Foundation Making a Difference”, available at: https://ukcsc.co.uk/suver-nuver-experience-cannabis-foundation-making-difference/ (accessed 25 January 2018).

ENCOD, (2011) "Code of Conduct for European Cannabis Social Clubs", available at: http://www.encod.org/info/CODE-OF-CONDUCT-FOR-EUROPEAN.html (accessed 25 January 2018).

Fine, D. (2012) Too High to Fail, Cannabis and the New Green Economic Revolution, Gotham Books, New York.

Haidt, J. (2012) The Righteous Mind: Why Good People are Divided by Politics and Religion, Penguin Books, London. 
Hari, J. (2015) Chasing the Scream: The First and Last Days of the War on Drugs, Bloomsbury, London.

HM Government (2010) Reducing Demand, Restricting Supply, Building Recovery: Supporting People to Live a Drug Free Life. Available at: https://www.gov.uk/government/uploads/system/uploads/attachment_data/file/98026/drug-strategy2010.pdf (accessed 23 January 2018).

HM Government (2017) 2017 Drug Strategy. Available at: https://www.gov.uk/government/uploads/system/uploads/attachment_data/file/628148/Drug_strategy 2017.PDF (accessed 23 January 2018).

INCB, (2017) Narcotic Drugs: Estimated World Requirements for 2018. Available at: https://www.incb.org/documents/Narcotic-Drugs/TechnicalPublications/2017/Narcotic_drugs technical_publication_2017.pdf (accessed 5 March 2018).

Lancaster, K., Seear, K., Treloar, C. and Ritter, A. (2017) "The productive techniques and constitutive effects of 'evidence-based policy' and 'consumer participation' discourses in health policy processes" Social Science \& Medicine, 176: 60-68.

Medican Campus, (n.d.) "Medican Campus", available at: http://www.medican.uk/index.php (accessed 24 January 2018).

NORML (n.d.), "NORML Daily Audio Stash", available at: http://marijuanapodcasts.com/shows/norml-daily-audio-stash (accessed 25 January 2018).

NORML-UK (n.d.), "NORM UK: Working to reform cannabis laws", available at: http://normluk.org/ (accessed 24 January 2018).

Ritter, A., Lancaster, K. and Diprose, R. (2018) "Improving drug policy: The potential of broader democratic participation", International Journal of Drug Policy, 55: 1-7.

Roberts, M. (2014) "Making drug policy together: Reflections on evidence, engagement and participation", International Journal of Drug Policy, 25(5): 952-956.

Rolles, S. and Murkin, G. (2013) How to regulate cannabis, a practical guide, Transform Drug Policy Foundation, 1st Edition, Bristol, available at: http://www.tdpf.org.uk/resources/publications/howregulate-cannabis-practical-guide (accessed 23 January 2018)

Rolles, S. (2017) NoNonsense Legalizing Drugs: The key to ending the war, New Internationalist Publications, Oxford.

Sentencing Council, (2012) Drug Offences, Definitive Guideline. Available at: https://www.sentencingcouncil.org.uk/wpcontent/uploads/Drug_Offences_Definitive_Guideline_final_web1.pdf (accessed 24 January 2018).

Starling, B. (2016) Tide Effect: How the world is changing its mind on cannabis legalisation, Volteface Publications, London, available at: http://volteface.me/publications/tide-effect/ (accessed 24 January 2018).

UKCSC (n.d.) "United Kingdom Cannabis Social Clubs", available at: https://ukcsc.co.uk/ (accessed 23 January 2018).

UKCSC (2014) “UKCSC Operations Manual”, available at: https://ukcsc.co.uk/wpcontent/uploads/2014/04/v-2.2-The-UK-Model-UKCSC-full-doc.pdf (accessed 24 January 2018). 
Page 13 of 13

Drugs and Alcohol Today

$$
\begin{aligned}
& 1 \\
& 2 \\
& 3 \\
& 4 \\
& 5 \\
& 6 \\
& 7 \\
& 8 \\
& 9 \\
& 10 \\
& 11 \\
& 12 \\
& 13 \\
& 14 \\
& 15 \\
& 16 \\
& 17 \\
& 18 \\
& 19 \\
& 20 \\
& 21 \\
& 22 \\
& 23 \\
& 24 \\
& 25 \\
& 26 \\
& 27 \\
& 28 \\
& 29 \\
& 30 \\
& 31 \\
& 32 \\
& 33 \\
& 34 \\
& 35 \\
& 36 \\
& 37 \\
& 38 \\
& 39 \\
& 40 \\
& 41 \\
& 42 \\
& 43 \\
& 44 \\
& 45 \\
& 46 \\
& 47 \\
& 48 \\
& 49 \\
& 50 \\
& 51 \\
& 52 \\
& 53 \\
& 54 \\
& 55 \\
& 56 \\
& 57 \\
& 58 \\
& 59 \\
& 60
\end{aligned}
$$

13 